\title{
TRỐNG ĐÔNG SƠN - BẰNG CHÚNG CỦA GIAO LU'U \\ VĂN HÓA ĐÔNG SƠN VỚI CÁC NỀN VĂN HÓA Ở ĐÔNG NAM Á
}

\author{
Dong Son bronze drums - a proof of cultural exchange between Dong Son \\ and other cultures in Southeast Asia
}

Ngày nhận bài: 01/9/2016; ngày phản biện: 15/10/2016, ngày duyệt đăng: 22/3/2017

\section{Trịnh Sinh* \\ Nguyễn Sỹ Toản**}

\section{TÓM TẮT}

Trống đồng nói chung và trống Đông Sơn nói riêng là di sản văn hóa độc đáo thu hút sự quan tâm nghiên cứu của nhiều học giả trong và ngoài nước. Vấn đề nguồn gốc, sự phân bố và phân loại trống đồng được các nhà nghiên cứu đặc biệt chú ý và đề cập khá nhiều trong các công trình nghiên cứu của mình. Căn cứ vào đặc điểm và hình dáng của trống đồng $F$. Heger đã phân chia thành bốn loại chính. Trong đó trống loại I (Heger I) có niên đại sớm nhất và được các nhà nghiên cứu đồng nhất với trống Đông Sơn. Những chiếc trống đồng Đông Sơn đã có mặt ở nhiều vùng đất xa xôi mà theo các nhà khảo cổ học của những nước Đông Nam Á thì những nơi này vào thời đó không đúc trống đồng mà trống đồng đem tới từ miền Bắc Việt Nam. Vì thế, việc có mặt trống Đông Sơn đây đó ở Đông Nam Á chắc chắn là do sự giao lưu của vùng đất này với cư dân Đông Sơn.

Từ khóa: trống đồng; trống Đông Son; Đông Nam Á.

\begin{abstract}
Bronze drums in general and Dong Son bronze drums in particular are unique cultural heritage attracting the attention of many domestic and international scholars. The issues of origin, distribution and category of bronze drums were specially noticed and much mentioned by researchers in their works. Based on the characteristics and shapes of bronze drums, F. Heger divided them into four main categories, in which Class I (Heger I) dated to the earliest and was considered to be identical to Dong Son bronze drums by researchers. Dong Son bronze drums have been present in distant lands. According to the archaeologists in Southeast Asia, bronze drums were not casted in those lands, but they were brought from North Vietnam. Therefore, the presence of Dong Son bronze drums in Southeast Asia was undoubtedly due to the exchange between these lands with Dong Son residents.
\end{abstract}

Key words: drum; Dong Son drums; South East Asia.

Có thể nói, sự phấn bố của trống đồng ở Đông Nam Á luôn là điều quan tâm của nhiều nhà khảo cổ học nghiên cứu khu vực này. Đã có nhiều ý kiến đưa ra để giải thích sự phân bố rộng của trống đồng ở Đông Nam Á. Trong bài viết này chúng tôi đề cập đến mối liên hệ giữa văn hóa Đông Sơn và một số nền văn hóa khác ở Đông Nam Á như: Inđônêxia, Thái Lan, Malaixia, Lào, Cămpuchia.
1. Inđônêxia: Văn hóa Đông Sơn có mối liên hệ qua lại với vùng quần đảo Inđônêxia thời đó không chỉ thể hiện ở trống đồng mà còn ở một số tập tục, khi mà ta thấy kiểu nhà sàn mái cong trên trống đồng Ngọc Lũ lại được bảo tồn gần như nguyên vẹn hình dáng trong các nếp nhà sàn hiện nay ở một số đảo nơi đây. Yếu tố hải đảo trong văn hóa Đông Sơn còn thể hiện ở một số di 
chỉ Đông Sơn ven biển như di chỉ Đầu Rằm, huyện Yên Hưng, tỉnh Quảng Ninh có sự tồn tại một số đồ trang sức bằng vỏ sò, vỏ ốc, kỹ nghệ chế tác công cụ bằng vật dụng từ biển rất giống ở các đảo ven bờ Thái Bình Dương suốt từ nam Nhật Bản đến bờ biển Thái Lan...

Trong thời điểm ở Việt Nam có nền văn hóa Đông Sơn phát triển thì ở Inđônêxia cũng bước vào buổi đầu của một thời đại đồ đồng thau - sắt sớm với những sắc thái văn hóa bản địa như văn hóa cự thạch, người chết chôn trong vò... (H.R. Van Heekeren 1958), tuy nhiên cũng chỉ phát hiện chủ yếu là các hiện vật đồ đồng lẻ tẻ, nhiều chiếc rìu đồng ở đây lại khá giống rìu đồng loại có chuôi xòe hình cánh én như loại hình rìu đồng Làng Vạc và nhiều trống đồng Đông Sơn. Một số tượng kim loại và gố ở đây cũng mang phong thái của tượng trên cán dao găm hình người Đông Sơn.

Đặc biệt ở vùng quần đảo Inđônêxia, chứng tích của các trống đồng Đông Sơn để lại khá nhiều trên các đảo. Một số trống đồng điển hình như trống Xiandua, đảo Java. Đảo này còn có nhóm trống Xơmarang, trống Dieng. Trên đảo Xumbava, có nhóm trống Xanghi gồm 6 chiếc là trống Đông Sơn trang trí đẹp. Trên các đảo Roti, Salayar và nhiều đảo nhỏ khác cũng tìm thấy khá nhiều trống Đông Sơn. (F. Heger 1902). Quần đảo Kai, gần Irian Jaya, có lẽ là vùng tìm thấy trống đồng Đông Sơn xa nhất về phía đông mang dấu tích giao lưu văn hóa.

Theo các học giả Indonexia (H. Soebadio et al.1996: 38-40), đồ đồng và đồ sắt xuất hiện ở Indonexia muộn, khoảng 500 năm trước Công nguyên, chủ yếu là đồ đồng nghi lễ. Trống đồng Đông Sơn có mặt ở quần đảo này muộn hơn, có thể là được du nhập từ miền Bắc Việt Nam vào khoảng 200 năm trước Công nguyên (Hình minh họa 1). Sau khi du nhập trống đồng, người dân bản địa ở đây lại sáng tạo ra một dòng trống mới: trống Moko, vừa có những nét của trống Đông Sơn lại vừa có những nét riêng bản địa.

Một số trống đồng tìm được ở Inđônêxia là những trống Đông Sơn điển hình, mang dáng dấp của trống Hữu Chung của Việt Nam. Chúng tôi cũng đồng ý với ý kiến của các học giả Inđônêxia rằng trống đồng Đông Sơn đó đến đất nước này theo một dạng như "nhập khẩu" nguyên chiếc, để sau đó, từ những trống này đã gợi ý cho một mẫu hình trống được đúc tại chỗ. Niên đại của trống Đông Sơn đến đây có thể không sớm quá thế kỷ thứ II trước Công nguyên. Các nhà khảo cổ Inđônêxia đã công bố tư liệu về hai mộ táng tìm được trống đồng $(\mathrm{H}$. Soebadio et al.1996: 38-40) ở Plawangan, miền Trung đảo Java. Trống Đông Sơn tìm được trong mộ trẻ em, một mộ còn nguyên xương sọ. Đồ tùy táng trong mộ là hạt chuỗi thủy tinh, hạt chuỗi vàng, thùng đồng 4 chân có hoa văn vòng tròn kiểu Đông Sơn, giáo và đục bằng sắt, đồ gốm, đồ gỗ... Đáng lưu ý, trong một ngôi mộ trẻ em, một chiếc trống Đông Sơn được đặt nằm trên một chiếc trống thứ hai, nhưng là trống đúc tại bản địa, loại trống Pejeng. Điều đó chứng tỏ một giai đoạn mà trống nhập khẩu tồn tại cùng trống bản địa và người Inđônêxia quý trọng cả hai loại trống này.

Theo thống kê tìm được 28 chiếc trống đồng Đông Sơn ở khắp các hòn đảo nơi đây (Phạm Minh Huyền, Nguyễn Văn Huyên, Trịnh Sinh 1987: 205). Đó là những trống đồng đến từ miền Bắc Việt Nam theo những dòng hải lưu ven biển và sự giao lưu giữa các cộng đồng cư dân hai khu vực. Vào thời điểm này, với cơ sở vật chất, xã hội trên các đảo Inđônêxia bấy giờ chưa thể nảy sinh ra một dạng nhà nước sơ khai nhưng đã có những thủ lĩnh cộng đồng nhỏ và có những mối giao lưu với khu vực miền Bắc Việt Nam. Trong nhiều tác phẩm viết về vùng quần đảo của mình, $\mathrm{P}$. 
Bellwood cũng cho rằng giữa miền Bắc Việt Nam và vùng quần đảo Inđônêxia cũng có những mối liên hệ giữa các nhóm cư dân (P. Bellwood 1997).

2. Thái Lan: Con đường giao lưu ven biển Thái Lan cũng cho thấy sự có mặt của nhiều trống đồng Đông Sơn, nhưng cũng có những trống đồng tìm được ở sâu trong nội địa. Chúng tôi đã nghiên cứu 22 chiếc trống đồng Đông Sơn tìm được ở đây. Có trống tìm được trong hang Ongbah (P. Sorensen 1979) có trống tìm được trên đảo ven bờ như trống Kosamui (Trịnh Sinh 1998: 93). Trống có tên gọi là trống Côxamui, tỉnh Xurathani, miền Nam Thái Lan, chỉ cách bờ biển $300 \mathrm{~m}$. Trống có đường kính mặt $69 \mathrm{~cm}$ chiều cao $54,5 \mathrm{~cm}$. Giữa mặt trống trang trí ngôi sao 10 cánh, có những hoa văn Đông Sơn khác như hoa văn người hóa trang, 10 chim bay, hình thuyền, hoa văn hình học (S. Vallibhotama 1978: 5572). Hai chiếc trống Ongbah 86 và Ongbah 89 tìm được trong một quan tài hình thuyền và được định niên đại theo dấu vết gỗ bị cháy ở đây theo phương pháp C 14 là: $230 \pm 100$ năm trước Công nguyên. Với niên đại được định như vậy thì khi đó, ở miền Bắc Việt Nam đang tồn tại nhà nước sơ khai Văn Lang - Âu Lạc. Như vậy, có thể rút ra một điều: cư dân Việt cổ của nhà nước sơ khai Việt Nam đã có sự giao lưu văn hóa với cư dân cổ đại Thái Lan.

3. Malaixia: (phần đất liền) là một vùng bán đảo, vào thời đại Kim khí ở đây, tìm được một số đồ đồng thau như rìu và một số khuôn đúc chứng tỏ có công nghệ đúc đồng tại chỗ. Tuy nhiên, đồ đồng ở đây còn phát hiện không nhiều. Đáng lưu ý là có 6 chiếc trống đồng Đông Sơn tìm được nơi đây, có thể được mang tới từ miền Bắc Việt Nam theo đường biển. Điển hình là hai chiếc trống Cuala Torengganu I và II ở bờ phía đông của bán đảo nước này. Vùng Kampon Sungailang cũng tìm được 2 trống Đông Sơn cùng được chôn ngửa trong một vũ gốm và trống được trang trí hoa văn hiện thực khá đẹp như chim bay, hình người hóa trang lông chim, tượng cóc. (B.A.V. Peacock 1965). Có thể nói, vùng bán đảo Malaixia là vùng xa nhất về phía tây, cho đến nay tìm được những dấu tích của sự giao lưu văn hóa Đông Sơn.

Cũng còn phải kể đến những con đường giao lưu theo những thung lũng, ven sông suối nhỏ nằm sâu trong đất liền. Chúng ta tìm được nhiều đồ đồng, nhất là trống đồng Đông Sơn ở Lào, Đông Bắc Thái Lan và Cămpuchia.

4. Lào: Một số trống đồng Đông Sơn tìm thấy ở sâu trong địa phận Lào như trống Đon Đét, phát hiện năm 1924 trong khi làm đường từ Pắc Xế đi U Bon. Trống Phôn Xa Vẳn, tìm được ở Xa Vẳn $\mathrm{Na}$ Khệt. Trống Huổi Hủa Xang I và II cũng tìm được ở gần trống Phôn Xa Vẳn, cách Xa Vẳn $\mathrm{Na}$ Khệt khoảng $40 \mathrm{~km}$ về phía bắc. Trống Viêng Xay ở vùng mường Viêng Xay của tỉnh Sầm Nưa (Phạm Minh Huyền, Nguyễn Văn Huyên, Trịnh Sinh 1987).

Mới đây tại Lào đã phát hiện ra trống đồng Đông Sơn tại khu khai thác mỏ đồng Sê Pôn (Trịnh Sinh 2014: 217-220) (Hình minh họa 2 và 3 ).

Trong cuộc tọa đàm khoa học quốc tế về văn hóa Đông Sơn và nguồn gốc dân tộc Việt, tiến sĩ ThongLith Luangkhoth đã cung cấp thêm nhiều tư liệu không chỉ một chiếc trống được đào trong lòng đất ở Lào mới đây (ThongLith Luangkhoth 2014).

Năm 2005, tại nhà máy khai thác mỏ đồng Sê pôn trong tỉnh đã phát hiện trong lòng đất chiếc trống đồng kích thước lớn: cao 80 $\mathrm{cm}$; đường kính mặt $110 \mathrm{~cm}$. Hiện đang lưu giữ tại Bảo tàng Quốc gia Lào. (ThongLith Luangkhoth còn đưa ra một tư liệu khác nữa về chiếc trống này: phát hiện ngày 30 tháng 1 năm 2008 với chiều cao: 75,5 cm và đường kính $98,5 \mathrm{~cm}$. Một tài liệu khác nữa thì lại cho 
ngày phát hiện là 30 tháng 8 năm 2008). Như vậy, theo các báo cáo khoa học thì có 3 thời điểm phát hiện ra trống và 2 số đo đường kính mặt và chiều cao có sự lệch nhau. Nhưng có lẽ chỉ là 1 trống, căn cứ theo so sánh ảnh chụp mà chúng tôi có được. Trống có 4 cóc đang quay đít vào tâm trống, hoa văn giữa mặt là ngôi sao 12 cánh, người hóa trang lông chim cầm rìu xéo trang trí trên lưng trống Trống có hai đôi quai kép. Mỗi quai trang trí 8 hàng hoa văn bông lúa nằm dọc quai, các hoa văn hình học như hình thoi, răng cưa, vòng tròn chấm giữa tiếp tuyến.

Bên cạnh chiếc trống lớn trên, một trống đồng nhỏ hơn cũng tìm được ở khu vực Sê pôn và được lưu giữ, trưng bày ở nhà văn hóa của huyện Vilabuli. Đó là chiếc trống thứ hai, tìm được ngày 4 tháng 6 năm 2010 ở bản Phả Phỉ Lang, huyện Vilabuli trong tỉnh. Trống có chiều cao $48 \mathrm{~cm}$, đường kính mặt $63 \mathrm{~cm}$. Trống được trang trí ngôi sao 12 cánh. Trống không có tượng cóc. Trống có vành hoa văn chim bay có thể là 4 con, hoa văn hoa văn gạch ngắn song song, vòng tròn chấm giữa quen thuộc của văn hóa Đông Sơn. Trên mặt trống và thân trống còn có dấu vết con kê hình gần vuông.

Chiếc trống thứ ba đã bị vỡ nát, mất phần mặt, mất phần lớn tang trống. Trống tìm được vào tháng 3 năm 2001 ở bản Hốc Lào, huyện Sê pôn trong tỉnh. Chiều cao còn lại là $75 \mathrm{~cm}$. Đường kính khá lớn $127 \mathrm{~cm}$. Trống đang được trưng bày tại Bảo tàng $\mathrm{Sa}$ Vẳn $\mathrm{Na}$ Khệt. Trống có hai đôi vai kép, mỗi quai có 4 hàng hoa văn bông lúa nằm dọc. Phần lưng trống có hoa văn người múa hóa trang, hoa văn hình trám, vòng tròn chấm giữa tiếp tuyến, răng cưa quen thuộc của văn hóa Đông Sơn.

Chiếc trống Đông Sơn thứ tư chỉ còn phần mặt với đường kính $77 \mathrm{~cm}$, phát hiện được ở bản Kạ Bau, huyện Xay bu li trong tỉnh. Trống được trang trí ngôi sao 12 cánh giữa mặt. Giữa các cánh sao có hình hoa văn lông công, 10 chim bay, hoa văn hình người múa hóa trang cách điệu cao, hoa văn gạch ngắn song song, vòng tròn chấm giữa tiếp tuyến quen thuộc của trống Đông Sơn. Phần rìa mặt trống còn có dấu vết con kê đúc trống.

Qua phát hiện mới đây về trống Đông Sơn ở Lào, chúng tôi có vài nhận xét:

Nhóm trống 4 chiếc tìm được trong lòng đất $\mathrm{Sa}$ Vẳn $\mathrm{Na}$ Khệt vừa kể trên là trống Đông Sơn thực sự với cách đúc trống theo kiểu dùng hệ thống con kê trên mặt, trên thân còn để lại dấu tích kỹ thuật, trang trí các hoa văn đặc trưng Đông Sơn. Một số trống trong nhóm là trống Đông Sơn muộn, có hoa văn người múa hóa trang cách điệu cao, có kích thước lớn, gần với những trống tìm được trong lòng đất Việt Nam như trống Hữu Chung, Phú Phương, Đông Hiếu...

Địa bàn phát hiện trống cũng là nơi có mỏ đồng giàu trữ lượng, các nhà khoa học đã tìm được dấu tích khai thác mỏ ở đây, dấu tích của những thỏi đồng vừa được luyện, khuôn để đúc các thỏi đồng này. Vấn đề được đặt ra là: đây là nơi khai khoáng, nấu quặng thành thỏi đồng để cung cấp nguyên liệu cho nhiều vùng đúc đồng rộng lớn. Cho đến ngày nay, vùng Sê pôn vẫn là nơi khai thác đồng lớn của Lào. Nơi nào chuẩn bị khai mỏ thì đã thấy dấu tích khai mỏ với những hầm khai thác từ thời cổ đại. Vậy thì, liệu đây có phải là nơi đúc trống đồng?

Theo chúng tôi, đúc được trống đồng Đông Sơn là một kỹ nghệ khác với đúc những thỏi đồng nguyên liệu. Nơi đây có thể đúc số lượng lớn thỏi đồng, nhưng để đúc những trống lớn còn phải giỏi làm khuôn đất mà không phải chất đất ở đâu cũng làm được khuôn. Những trống đồng lớn ở đây có được chắc là có sự trao đổi giữa vùng nguyên liệu 
với vùng đúc trống. Chính vì trống Đông Sơn là sản phẩm quý, nên trong trường hợp chiếc trống ở đây đã bị vỡ nát ở mặt, tang, ở chân từ thời cổ đại, nhưng người xưa vẫn tận dụng bằng cách vá lại những phần vỡ bằng cách "khâu” lại bằng các sợi dây đồng. Chắc chắn nếu như đúc được trống lớn như vậy, lại sẵn nguyên liệu thì người cổ ở đây phải bỏ trống vỡ mà đúc lại trống cho hoàn chỉnh. Nhất là trống vỡ thì âm thanh sẽ kém đi nhiều, nhất là vỡ phần mặt trống. Nhưng vì không chuyên đúc trống, nên những người thợ khai mỏ mới phải tận dụng trống vỡ.

So sánh các trống ở Sa Vẳn $\mathrm{Na}$ Khệt, có thể xếp những trống có kích thước lớn, hoa văn người múa hóa trang cách điệu ở đây vào nhóm C tương đương nhóm trống Hữu Chung (Phạm Minh Huyền, Nguyễn Văn Huyên, Trịnh Sinh 1987), có niên đại khoảng thế kỷ II, I trước Công nguyên. Cũng cần lưu ý là nhóm trống Hữu Chung cũng đã có mặt ở vùng quần đảo Inđônêxia. Có thể nhóm trống này còn có mặt ở nhiều vùng khác nữa ngoài Việt Nam, đó là do có sự biến động lịch sử nào đó mà chúng tôi sẽ đề cập đến trong một chuyên luận khác.

5. Cămpuchia: Với những tài liệu mới nhất về phát hiện trống đồng loại I Heger ở Cămpuchia do Seng Sonetra công bố mới đây tại cuộc tọa đàm khoa học quốc tế Văn hóa Đông Sơn và nguồn gốc dân tộc Việt mới đây tổ chức tại Hà Nội (Seng Sonetra, A. Reinecke, Vin Laychour 2014), chúng ta thấy được một số lượng khổng lồ lên đến khoảng 60 chiếc trống được thông báo là đã tìm thấy và bị mua bán bất hợp pháp từ các di chỉ ở Bit Meas và Prohear. Tuy nhiên, chỉ có một chiếc trống được các nhà khảo cổ học khai quật khoa học, từ trong ngôi mộ số 4 của Prohear, đã gợi mở khá nhiều vấn đề về trống đồng và thời sơ sử ở vùng giáp biên giới Việt Nam của đất nước này.
Chiếc trống đồng mộ 4 Prohear (trong bài tạm gọi là trống Prohear) đã được công bố bản vẽ và ảnh trong cuốn sách The first Golden age of Cambodia: excavation at Prohear (A. Reinecke, Vin Laychour, Seng Sonetra 2009). Các tác giả cho rằng trống có chiều cao xấp xỉ $30,5 \mathrm{~cm}$ và đường kính mặt rộng nhất khoảng $45,0 \mathrm{~cm}$; trang trí ngôi sao 10 cánh, hình người múa hóa trang, 6 chim bay. Theo các tác giả trống gần gũi với trống Phù Lưu ở Quảng Bình và Trường Giang ở Thanh Hóa hơn là nhóm 4 trống đồng khai quật được ở Phú Chánh (Bình Dương). Các tác giả cho rằng có khả năng trống Prohear còn có dấu tích của 4 khối tượng cóc. Bản vẽ ở trang 80 của sách cũng thể hiện điều này (Hình minh họa 4).

Chúng tôi cũng đã tiếp xúc trực tiếp với trống đồng Prohear ở Bảo tàng Quốc gia Cămpuchia ở Phnom Penh trong một gian trưng bày dành riêng cho cuộc khai quật Prohear và đã có một vài nhận định như sau:

- Nghiên cứu sưu tập trống Phú Chánh đã được công bố (Bùi Chí Hoàng, Nguyễn Văn Quốc, Nguyễn Khánh Trung Kiên 2010: 347), chúng tôi thấy trống Prohear rất giống với trống Phú Chánh đến từng chi tiết, thể hiện ở các hoa văn mang tính đặc trưng như hình người múa hóa trang, chim bay, hoa văn hình học. Cả hai chiếc trống đồng này đều là trống không có tượng cóc. Theo chúng tôi, trống Prohear gần gũi với nhóm trống Phú Chánh hơn các trống nơi khác. Về mặt địa lý, dường như địa điểm Prohear gần với nhóm trống Phú Chánh hơn các địa điểm phát hiện trống đồng khác ở Việt Nam

- Chúng tôi cho rằng trống Prohear và nhóm trống Phú Chánh đều là trống Đông Sơn thực sự với kiểu dáng, hoa văn, kỹ thuật đúc hoàn toàn giống với trống Đông Sơn muộn.

Các nhà khoa học đã khai quật được trống Prohear trong một ngôi mộ giàu có nhất 
ở vùng này của một người phụ nữ quý tộc được đặt tên là "First Lady". Cùng tìm thấy trống đồng Đông Sơn là các đồ gốm bản địa, vòng đồng hình sừng trâu đeo cổ tay, công cụ sắt, dọi xe chỉ đất nung, hạt chuỗi và đồ trang sức bằng thủy tinh, mã não cùng với 13 hiện vật bằng vàng bạc như nhẫn, khuyên tai, trang sức trên đầu. Ngôi mộ số 4 có đồ tùy táng là trống đồng Đông Sơn muộn, đã được các nhà khoa học phân tích C14 mẫu than trong lòng trống, cho kết quả là năm 44 trước Công nguyên đến năm 51 sau Công nguyên.

Việc phát hiện trống Đông Sơn ở Prohear cũng như các nơi khác ở Cămpuchia đã gợi mở nhiều vấn đề về thời sơ sử ở đây. Có một điều có thể thấy được là trống Đông Sơn đã giao lưu khá rộng theo đường biển vào các cửa sông để đến các vùng đất phương Nam. Đến các vùng đất này, trống được coi là đồ tùy táng quý và được chôn cất cùng với hiện vật bản địa và theo phong cách bản địa: Ở Phú Chánh thì làm nắp đậy chum gốm mang phong cách $\mathrm{Sa}$ Huỳnh, ở Prohear thì người chết là phụ nữ quý tộc được đặt phần đầu của mình trong lòng trống Đông Sơn. Bên cạnh trống Đông Sơn, cũng có những hiện vật Đông Sơn điển hình như chiếc kiếm ngắn có chuôi là tượng một người phụ nữ trống nạnh cũng được phát hiện ở Cămpuchia và được trưng bày ở Bảo tàng Quốc gia Cămpuchia. Tuy nhiên, chúng tôi cũng chưa tìm hiểu được lý lịch chính xác của chiếc kiếm này.

-Niên đại xung quanh cột mốc Công nguyên đã có nhiều bằng chứng về sự tán phát trống đồng đi khắp các vùng Đông Nam Á lục địa và hải đảo. Đó cũng là thời điểm mà ở nơi đúc ra chúng là vùng Bắc Bộ Việt Nam đã có những biến động lịch sử lớn tác động đến việc trống đồng và có thể cả một số bộ phận cư dân Việt cổ nữa đã đến một số vùng đất mới. Đấy cũng là một vấn đề rất lý thú mà chúng tôi đã từng đề cập đến và cũng còn cần nhiều tư liệu nữa để chứng minh.

Vấn đề được đặt ra là vào thời điểm mà những chiếc trống đồng Đông Sơn đến các vùng đất Đông Nam Á vừa kể trên thì liệu các tộc người bản địa đã có hình thái nhà nước sơ khai chưa? Tài liệu thư tịch cổ cho thấy dường như khắp vùng Đông Nam Á khi đó chưa có một nhà nước sơ khai nào được ghi lại trong thư tịch. Nhưng liệu đã có một sự "ban phát" trống đồng như một biểu tượng quyền lực, một vật biểu trưng cho sự công nhận chính thức các thủ lĩnh gần như là một loại vương miện hay vương trượng mà ở một nơi nào đó ở phía Bắc Việt Nam ngày nay đã phải có một trung tâm nghi 1ê̂,, nơi đóng đô một tổ chức quyền lực ban phát đi những biểu tượng đó giống như các Giáo Hoàng xưa kia chăng? Những đoàn sứ giả từ xa đến đây để nhận lấy một chiếc trống mà có được chiếc trống đó, lãnh tụ bộ lạc đó sẽ trở thành Vua chính thống (LoofsWissowa 1981: 77).

Mọi vấn đề vẫn còn phải được nghiên cứu thêm nữa, nhưng dẫu sao, cũng phải ghi nhận sự gợi ý của học giả Loofs - Wissowa có một phần nào cho thấy: nhiều trống đồng biểu tượng của quyền lực đến các vùng Đông Nam Á ắt phải là sản phẩm được các thủ lĩnh trong vùng tôn trọng và nhiều khi chỉ thủ lĩnh mới là người được sử dụng các trống đồng này. Như vậy, một cách nào đó, trống đồng vẫn là đại biểu cho một sự giao lưu văn hóa giữa cộng đồng cư dân Văn Lang - Âu Lạc với các cộng đồng cư dân các tộc người đa dạng khác ở khắp khu vực. 


\section{TÀI LIỆ THAM KHẢO}

1. Bellwood P. (1997), Prehistory of the Indo - Malaixian Archipelago. Hawaii.

2. Bùi Chí Hoàng, Nguyễn Văn Quốc, Nguyễn Khánh Trung Kiên (2010), Khảo cổ hoc Bình Dưong (Từ Tiền sư đến Sơ sử). Nxb Khoa học xã hội, Hà Nội

3. Heger, F. (1902), Alte metalltramels aus sudost Asien. Leipzig.

4. Loofs-Wissowa H.H.E. (1981), Tiền sử và sõ sủ Đông Nam Á. Khảo cổ học số 1: 73-77.

5. Peacock B.A.V. (1965), The drums at Kampon Sungailang. MIN. Vol X

6. Phạm Minh Huyền, Nguyễn Văn Huyên, Trịnh Sinh (1987), Trống Đông Sơn. Nxb Khoa học xã hội, Hà Nội: 205;

7. Seng Sonetra, Reinecke A., Vin Laychour (2014), Bronze drums of the Dong Son culture in Southeastern Cambodia. The culture of Dong Son and the origin of Viet people. Workshop in Hanoi, October 8-10, 2014. A. Reinecke, Vin Laychour, Seng Sonetra 2009;

8. Soebadio H. et al.1996. Indonexian heritage: Ancient history. Jakarta. pp: 38-40;

9. Sorensen P. (1979), The Ongbah Cave and Its fifth drum. EAS. New York-Kualalumpur;

10. ThongLith Luangkhoth (2014), Giới thiệu so lược về nhũng phát hiện văn hóa Đông Sơn tại huyện Sepon, tỉnh Sa vẳn Na Khệt, Cộng hòa Dân chủ Nhân dân Lào. The culture of Dong Son and the origin of Viet people. Workshop in Hanoi, October 8-10, 2014;

11. Trịnh Sinh (1998), A comment on the bronze drums discovered in Thailand. Comparative Thai Vietnamese Archaeology: culture in Metal Age. Bangkok: 93-102: 93;

12. Trịnh Sinh (2014), Về nhóm trống Đông Sõn mói phát hiện ở Sa Vẳn Na Khệt (Lào). Những phát hiện mới về khảo cổ học năm 2014: 217-220;

13. Van Heekeren H.R. (1958), The bronze-iron age of Indonexia. S-Gravenhage- Martinus Nijhoff;

14. Vallibhotama S. (1978), The Progress of research into the prehistory of Thailand. In: Muang Boran. Vol. IV: 55-72.

\section{HÌNH MINH HỌA}

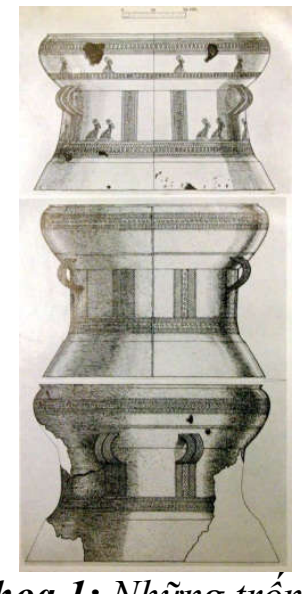

Hình minh họa 1: Nhũ̃ng trống đồng Đông Son tìm được ở đảo Java, Inđônêxia (Hình trên: trống ở Tjiandjur. Hình giũa: trống ở Semarang. Hìn dưới: trống ở Banjumas) (Nguồn: H. Van Heekeren 1958. Hình 8)

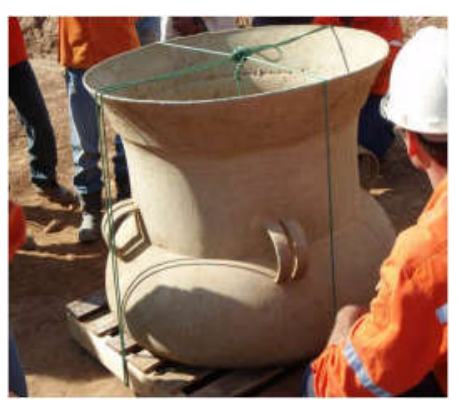

Hinh minh họa 2: Chiếc trống đồng Đông Sơn mới phát hiện trong lòng đất ở khu nhà máy khai thác mỏ đồng Sê Pôn, tỉnh Xa Vẳn Na Khệt 

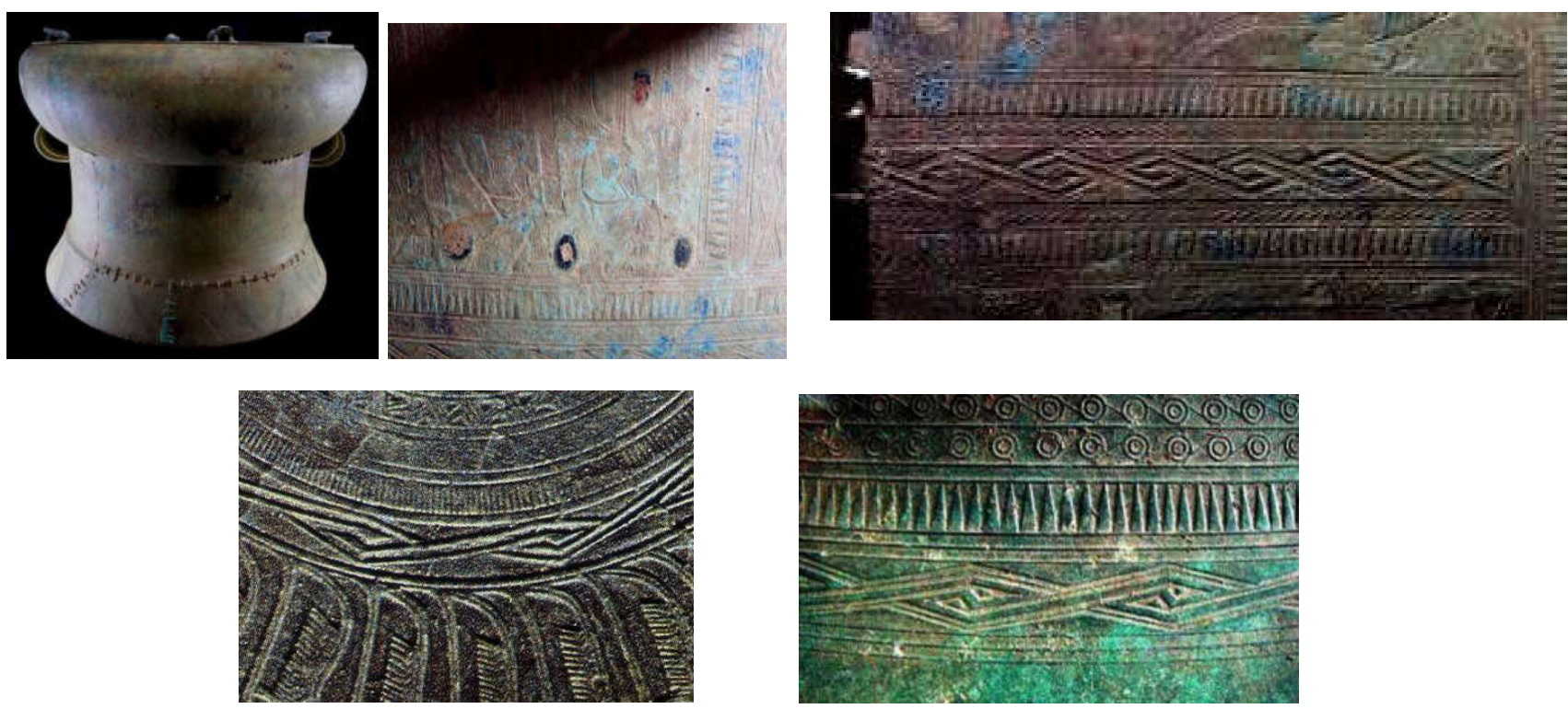

Hình minh họa 3. Hình trên: Trống Đông Sơn ở khu nhà máy khai thác mỏ đồng với hoa văn nguời múa hóa trang, hoa văn hình học đặc trung và dấu vết con kê trên thân trống.

Hình giũua: Hoa văn trên trống ở khu nhà máy khai thác mỏ đồng Sê pôn;

Hình dươii: So sánh hoa văn hình học đặc trung của trống Đông Sonn: Hình duới, trái: Trên trống Hũu Chung; Hình dưới, phải: trên trống Bản Hốc Lào
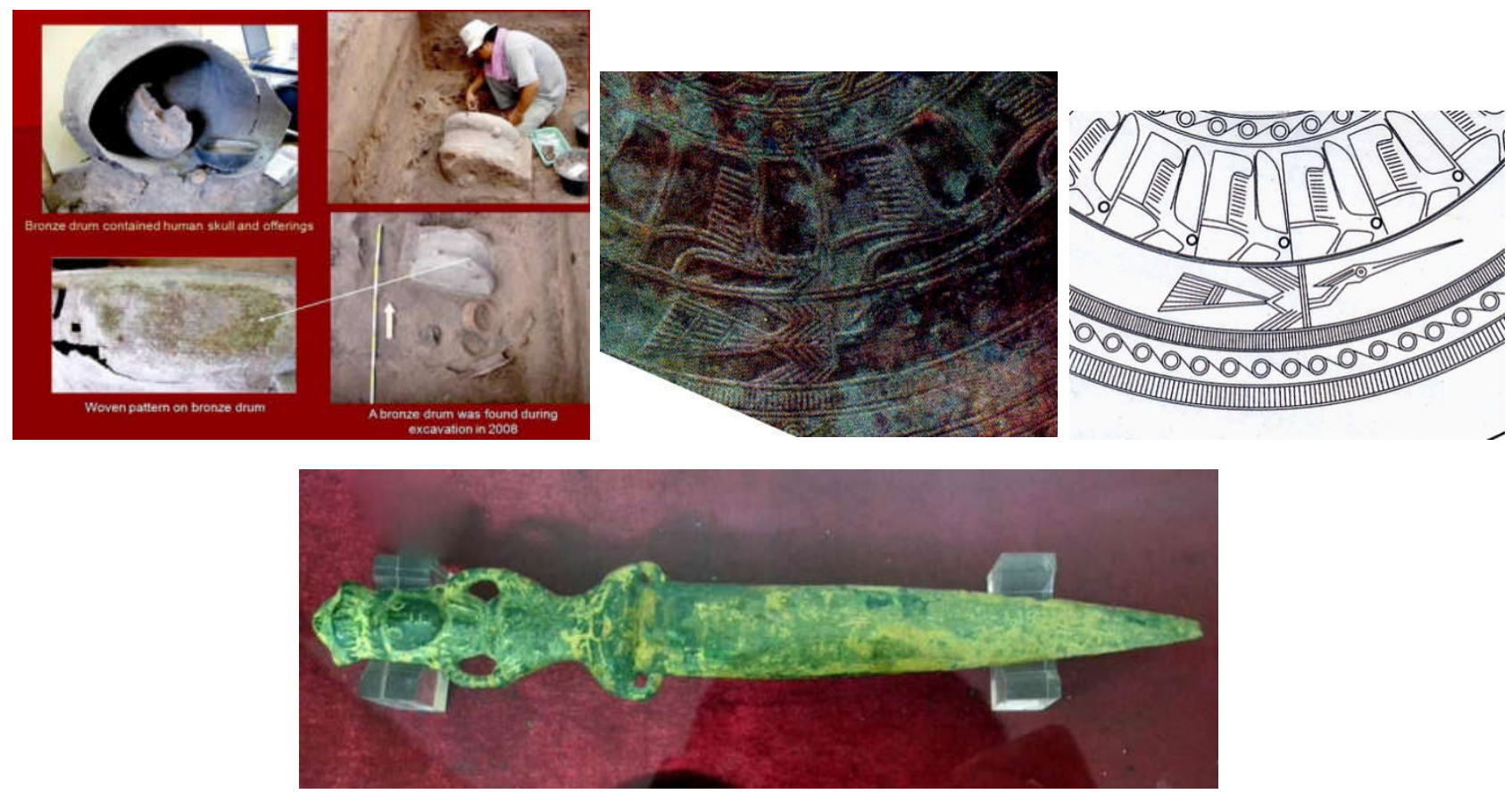

Hình minh họa 4. Hình trên: Trống đồng Đông Sơn chưa cốt so người và đồ tùy táng, khai quật tại Prohear, tỉnh Prey Veng, Cămpuchia năm 2008-2009 (Nguồn: Heng Sophady 2010)

Hình giũa: So sánh hoa văn đặc trung: Bên trái: trống đồng Phú Chánh. Bên phải: trống đồng Prohear (Cămpuchia)

Hình duới: Kiếm ngắn có cán tượng nguời trung bày ở Bảo tàng Quốc gia Cămpuchia 